\title{
Tranexamic acid (AMCA) in aneurysmal subarachnoid haemorrhage
}

\author{
H FODSTAD \\ From the Department of Neurosurgery, Umeå University Hospital, Umeå, Sweden
}

Subarachnoid haemorrhage due to a ruptured cerebral aneurysm is a dramatic event in neurosurgery and one of the most destructive. Its management is complicated by the risks of rebleeding and cerebral vasospasm and their sequelae. Rebleeding and vasospasm rarely occur before three days after the primary bleed. ${ }^{12}$ Angiographic vasospasm is seen most often 10 to 17 days after bleeding. ${ }^{3}$ Because of the brain's vulnerability during spasm many surgeons prefer to wait until two weeks after the primary bleed to obliterate the aneurysm. ${ }^{4}$ Sano and Saito $^{5}$ reported fatal postoperative vasospasm in patients operated upon on days 4 and 7 after a haemorrhage. However, the 'spasm period' coincides with the time when rebleeding is most likely. The incidence of rebleeding is highest at the end of the first week and at the beginning of the second after the primary bleed, and the mortality after the first recurrence is reported to be between $43 \%$ and $64 \%{ }^{16}$ Thus most surgeons accept spontaneous mortality due to either progressive deterioration or to rebleeding during the first and second week. The surgical mortality when the patient has recovered from this deterioration can be low. It is therefore necessary to look for ways of lessening the risk of rebleeding during the first critical two weeks.

The aim in treating patients with a ruptured aneurysm with antifibrinolytic agents is to prolong the duration of the formed blood clot within and about the wall of the aneurysm and thus prepare the way for mechanical repair of the rupture. Promising results with aminocaproic acid (EACA) $)^{7-11}$ and AMCA $^{12-19}$ have been reported. Others, however, found that these drugs had no effect on rebleedings. ${ }^{20-24}$ In this paper I report the results of two controlled clinical trials of the effect of AMCA on aneurysmal rebleeding, vasospasm, hydrocephalus, and circulatory disturbances.

\section{Patients and methods}

The trials were conducted over the years 1972 to 1978. The sealed-envelope technique was used instead of the double-blind method, since it was considered unethical to give placebo injections for a prolonged period. Only patients admitted to the hospital within three days after a subarachnoid haemorrhage due to a ruptured aneurysm and in whom treatment was started within 72 hours were included in the trials. The diagnosis was verified by spinal fluid (CSF) examination and cerebral angiography. In the second series all patients were also examined with CT-scan.

The patients were randomly assigned to conservative treatment (bedrest and sedation) or conservative treatment together with the administration of AMCA. In a first series of 46 patients 23 were given AMCA by slow intravenous injection in a dosage of $1 \mathrm{~g}$ 4-hourly during the first week, $1 \mathrm{~g}$ 6hourly during the second to fifth weeks inclusive, and $1 \mathrm{~g} 8$-hourly during the sixth week: In a second series of 59 patients 30 received AMCA in hourly intravenous infusions $6 \mathrm{~g}$ daily during the first week, $4 \mathrm{~g}$ daily during the second week, and $1.5 \mathrm{~g}$ by mouth four times a day during the third to sixth weeks. The patients who received AMCA were treated according to this scheme until rebleeding, operation, discharge, or death. Thus not all patients were treated throughout the entire six weeks.

Hypotensive drugs and corticosteroids were given in most cases in both groups. The patient's clinical condition on admission was assessed according to Botterell et al. ${ }^{25}$ Evidence of rebleeding was verified by lumbar puncture, CSF spectrophotometry, ${ }^{26}$ CT-scan, or angiography. Repeated preoperative CT-scans and echo-encephalograms were performed to detect possible haematoma and hydrocephalus. The incidence of vasospasm was observed by repeated angiograms. The diameters of the internal carotid, middle cerebral, and anterior cerebral arteries were measured and compared with the diameters of the same vessels on the admission angiograms. ${ }^{27}$

\section{Results}

FIRST SERIES

Twenty-three of the 46 patients were controls and 68 
23 were treated with AMCA. The groups were similar for sex and condition on admission. The mean age for men was 45 years (range 23-68) and for women 51 years (range 29-66). Eight patients in the AMCA-treated group and 10 in the control group had a history of arterial hypertension. Nineteen treated patients and 16 controls were operated on, usually with obliteration of the aneurysm, at an average of 16 and 18 days respectively after the primary bleed.

One patient in the AMCA-treated group had a fatal rebleed and died 33 days after the primary bleed. Nine patients in the control group rebled 3 to 34 days after the primary. Three patients rebled twice and three died from it. The difference in the incidence of rebleeding between the two groups is statistically significant (Fisher's exact probability test $\mathbf{P}<0.01$ ).

In the AMCA-treated group two additional patients died of cerebral ischaemia, one of them after operation. Repeated preoperative angiograms showed an increased incidence of vessel narrowing among the AMCA-treated patients. ${ }^{28}$ Certain clinical findings such as impaired consciousness, with or without hemiparesis, were more prevalent in AMCA-treated patients with radiographically proved spasm than in those without. Ventricular dilatation usually developed 2-3 weeks after the first bleeding, was most pronounced after 2-3 months, and then decreased with no difference between the two groups. Only one patient in the control group needed a shunt. Deep venous thrombosis in the legs developed in two AMCA-treated patients and in one control patient. Two control patients had a suspected myocardial infarction. During the mean follow-up period of 18 months (range 3 to 34 ) a total of six treated patients and 10 controls died of various causes. The morbidity was similar in the two groups on discharge of the patients as well as during follow-up.
SECOND SERIES

Twenty-nine of the 59 patients in this series were controls and 30 were treated with AMCA. The groups matched for sex and condition on admission. The mean age for men was 44 years (range 27 to 72 ) and for women 55 years (range 19 to 73). Hypertension was noted in seven AMCA-treated and 12 control patients. In the AMCA-treated group a total of 14 patients were operated on at an average of 14 days after the primary bleed, whereas 22 patients in the control group were operated on on average 16 days after bleeding.

In the AMCA-treated group there were six rebleedings in six patients occurring 7 to 24 days after initial bleed. Five of them died. In the control group seven patients rebled 3 to 19 days after the initial bleed. Two patients rebled twice and one rebled three times. Five of the patients died from their recurrent bleedings. There was thus a higher rebleeding rate among the AMCA-treated patients in the second series as compared with the first one. This leads us to consider the way of administering AMCA, since the one difference between the two series was the route by which AMCA was given. In the first series it was given by slow intravenous injection for the entire six weeks, and in the second series it was given by intravenous infusion for the first two weeks and then by mouth.

To find out the comparative uptake of AMCA when given by jntravenous injection, infusion, or mouth we studied the concentration of the drug ${ }^{29}$ and fibrinolytic split products ${ }^{30}$ in the CSF in six patients, two of whom received the drug intravenously by injection, two by infusion, and two by mouth. The CSF concentration of AMCA reached $2 \mathrm{mg} / 1$ (which was considered therapeutic ${ }^{31}$ ) within 48 hours in all six patients (Figure). Concomitantly CSF fibrinolytic split products fell regardless of the route of AMCA administration. We concluded, therefore, that the method of giving

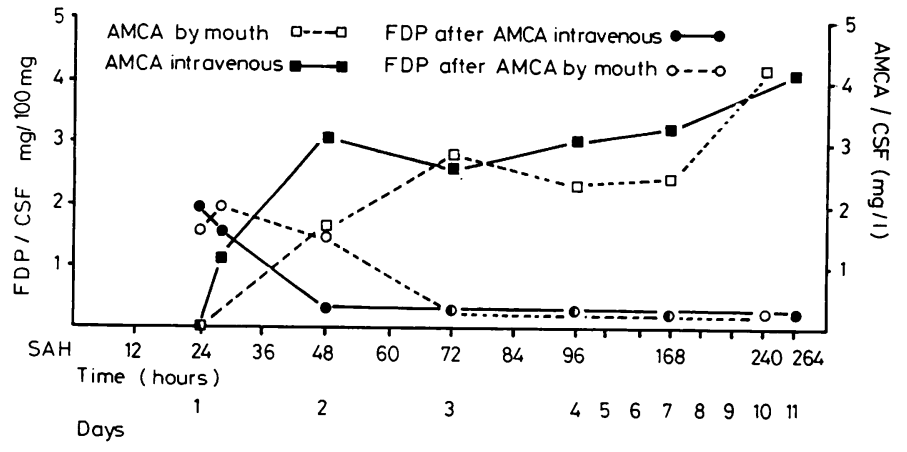

Fig. Concentrations of fibrinolytic split products $(F D P)$ and tranexamic acid $(A M C A)$ in cerebrospinal fluid $(C S F)$ after giving AMCA intravenously or by mouth. After 48 hours concentration of $A M C A$ is $2 \mathrm{mg} / \mathrm{l}$ and that of FDP unmeasurable regardless of route of administration of $A M C A$. SAH = Subarachnoid haemorrhage. 
the drug probably did not affect the rebleeding rate.

Four additional AMCA-treated patients and two controls died of cerebral ischaemia. The majority of patients in each group were examined repeatedly with preoperative angiograms and 19 of the treated and 17 of the control patients showed spasm. Two of the treated patients showed spontaneous aneurysmal thrombosis during treatment. Both had pronounced angiographic spasm..$^{32}$ Eleven treated and seven control patients had preoperative ventricular dilatation. After three to 41 months eight treated patients and 12 controls had slight to moderate ventricular dilatation. Two of the treated patients required a shunt. Deep venous thrombosis in the legs developed in two treated patients and three controls, whereas four treated and one control patient had pulmonary embolism. Four treated and one control patient developed myocardial infarction. Thus thromboembolic complications occurred more often in the AMCA-treated patients. The mean follow-up period was 25 months (range 2 to 41 ). By then a total of 22 patients had died -13 treated and 9 control patients. The morbidity was similar in the two groups.

\section{Discussion}

Six controlled clinical trials of the use of AMCA in subarachnoid haemorrhage have been reported ${ }^{1516}$ 1823242833 (see Table 1). Three reported that AMCA had a positive effect in preventing rebleeding, whereas the others reported practically no difference in the rebleeding rate between AMCA-treated patients and controls. Nevertheless, some factors might have influenced the latter results. Firstly, van Rossum and coworkers ${ }^{23}$ did a multicentre study, and in some of the patients treatment started late. Only 25 out of 51 patients underwent cerebral angiography, which leaves doubt about the diagnosis of ruptured aneurysm. Furthermore, three patients had diabetes mellitus. Glucose increases blood fibrinolytic activity ${ }^{34} 35$ and antidiabetic drugs influence the fibrinolytic activity of blood..$^{36-38}$ One of van Rossum's patients had nephritis, and AMCA should not be given to patients with impaired renal function. ${ }^{39}$ Finally, four of his patients were receiving anticoagulants, which could also have influenced the rebleeding rate. In Kaste and Ramsay's series nine patients did not have their rebleedings confirmed by lumbar puncture or neuroradiology. It is difficult clinically to differentiate between rebleeding and vasospasm. This could therefore be a source of error in Kaste and Ramsay's series. The total rate of rebleeding in all six series was thus $19 \%$ with $11 \%$ mortality among 156 treated patients and $30 \%$ rebleedings with $18 \%$ mortality among the 153 control patients.

Despite my comments on van Rossum's and Kaste and Ramsay's series, Table 1 shows a clear reduction in rebleedings among AMCA-treated patients whereas the difference in mortality from rebleeding between AMCA-treated patients and controls is rather small. If we compare the incidence of rebleeding in our two series 151633 there is an astonishing difference between the one out of 23 AMCA-treated patients and the nine out of 23 controls in the first series and the corresponding six out of 30 and seven out of 29 in the second series (Table 2).

A total of seven patients $(13 \%)$ in the AMCAtreated group had seven rebleedings at the 16th day on average after the initial haemorrhage, whereas 16 control patients $(31 \%)$ had 22 rebleedings on the 10 th day on average. The difference in rebleeding rate between the two groups is statistically significant $(P<0.05)$. Most of the recurrent bleedings in the control group occurred during the first weekearlier than in the AMCA-treated group. A total of six treated patients and eight controls died from their rebleedings. In addition, seven treated patients and two controls died from cerebral ischaemia. The total mortality from rebleeding and spasm/ischaemia was $25 \%$ in the AMCA-treated group and $19 \%$ in the control group during the six weeks' observation (Table 2). The morbidity was the same in both groups.

Table 1 Rebleedings and subsequent deaths in controlled clinical trials of AMCA in the treatment of subarachnoid haemorrhage

\begin{tabular}{|c|c|c|c|c|}
\hline & \multicolumn{2}{|l|}{$A M C A$} & \multicolumn{2}{|l|}{ Controls } \\
\hline & Rebleedings & Deaths & Rebleedings & Deaths \\
\hline $\begin{array}{l}\text { Fodstad et } a l^{1516} \\
\text { Van Rossum et } a l^{23} \\
\text { Maurice-Williams } \\
\text { Chandra } \\
\text { Kaste and Ramsay } \\
\text { Fodstad et } a l^{33}\end{array}$ & $\begin{array}{r}1 / 23 \\
5 / 26 \\
6 / 25 \\
1 / 20 \\
11 / 32 \\
6 / 30\end{array}$ & $\begin{array}{l}1 / 23 \\
4 / 26 \\
3 / 25 \\
1 / 20 \\
3 / 32 \\
5 / 30\end{array}$ & $\begin{array}{r}9 / 23 \\
4 / 25 \\
14 / 25 \\
4 / 19 \\
8 / 32 \\
7 / 29\end{array}$ & $\begin{array}{r}3 / 23 \\
3 / 25 \\
10 / 25 \\
4 / 19 \\
3 / 32 \\
5 / 29\end{array}$ \\
\hline Total & $30 / 156(19 \%)$ & $17 / 156(11 \%)$ & $46 / 153(30 \%)$ & $28 / 153(18 \%)$ \\
\hline
\end{tabular}


Table 2 Total mortality from rebleeding or cerebral ischaemia in controlled clinical trials of AMCA in the treatment of two series of patients ${ }^{15} 1633$ with subarachnoid haemorrhage over a period of six weeks

\begin{tabular}{|c|c|c|}
\hline & $A M C A$ & Controls \\
\hline \multicolumn{3}{|l|}{ Series $1^{1516}$} \\
\hline Deaths from rebleeding & $1 / 23$ & $3 / 23$ \\
\hline Deaths from ischaemia & $2 / 23$ & $\mathrm{C} / 23$ \\
\hline Total & $3 / 23$ & $3 / 23$ \\
\hline \multicolumn{3}{|l|}{ Series $2^{3 s}$} \\
\hline Deaths from rebleeding & $5 / 30$ & $5 / 29$ \\
\hline Deaths from ischaemia & $5 / 30$ & $2 / 29$ \\
\hline Total & $10 / 30$ & $7 / 29$ \\
\hline \multicolumn{3}{|l|}{ Both series } \\
\hline Total & $13 / 53(25 \%)$ & $10 / 52(19 \%)$ \\
\hline
\end{tabular}

In a co-operative aneurysm study Nibbelink ${ }^{9}$ concluded that antifibrinolytic therapy combined with antihypertensive medication caused a higher rate of rebleeding and mortality than antifibrinolytic therapy alone. In our series, one AMCA-treated patient who had a rebleed was taking chlorpromazine, which prolongs the bleeding time ${ }^{40}$ and increases blood noradrenaline. ${ }^{41}$ This in turn might increase the fibrinolytic activity of blood. 4243 Other drugs that might have influenced fibrinolysiscoagulation and thus the rebleeding rate in our patients were corticosteroids $44 \mathbf{4 5}$ and radiographic contrast media. ${ }^{46}$ The raised intra-arterial pressure during injection of contrast material could also have initiated the aneurysmal rupture in one AMCAtreated patient who rebled during control angiography on the 6th day of treatment. ${ }^{47}$

However, we have no satisfactory explanation for the difference in the incidence of rebleeding between the two AMCA-treated series, nor do we know why there was a high incidence of cerebral ischaemia among AMCA-treated patients. From their experience of a single or a limited number of cases several authors have expressed concern about an increased incidence of thrombotic and cerebral ischaemic complications associated with antifibrinolytic drugs. 48-52 This impression is confirmed by our findings. The sympathomimetic property of $\mathrm{AMCA}^{53}$ causing vasospasm and reducing cerebral blood flow must be considered. Earlier experimental work $^{54-56}$ showed that a direct toxic effect of antifibrinolytic agents on the arterial vessel wall could be of importance. Finally, there is the possibility of interaction with other drugs and substances causing secondary vessel wall changes and circulatory disturbances.

We cannot comment on the incidence of other circulatory complications. Theoretically antifibrinolytic drugs may prevent the dissolution of clots in the subarachnoid space and promote basal arachnoiditis with secondary hydrocephalus. We found more adhesions around the aneurysms at operation in AMCA-treated patients. Knibestöl et al ${ }^{57}$ found ventricular dilatation in $63 \%$ of 93 AMCA-treated patients and $39 \%$ of 51 controls. In a later follow-up examination, however, there was no difference between the groups. Park ${ }^{58}$ found a $43 \%$ incidence of ventricular dilatation in 46 patients treated with EACA against $17 \%$ in 48 controls. We did not see any more persistent ventricular dilatations in patients treated with AMCA.

The results of our studies support the hypothesis that the risk of rebleeding in patients with haemorrhage due to ruptured cerebral aneurysm is less when they are treated with AMCA during the first two weeks. Nevertheless, AMCA seems to produce cerebral ischaemic complications. This leaves us with the important question: Is it justified to give antifibrinolytic drugs in the preoperative management of patients with subarachnoid haemorrhage? On the basis of our two series we suggest that AMCA be given for only one to two weeks after the primary bleed. Its value in preventing rebleeding must be weighed against its possible side effects.

This investigation was approved by the Ethical Committee at the Umea University Hospital and by the Swedish National Board of Health and Welfare, Department of Drugs.

\section{References}

${ }^{1}$ Locksley HB. Report on the Co-operative Study of Intracranial Aneurysm and Subarachnoid Hemorrhage. Section V, part II. Natural history of subarachnoid haemorrhage, intracranial aneurysms and arteriovenous malformations. J Neurosurg 1966;25: 321-68.

${ }^{2}$ Symon L, Du Boulay G, Ackerman RH, Dorsch NWC, Shah SH. The time-course of blood-induced spasm of cerebral arteries in baboons. Neuroradiology $1973 ; 5: 40-2$.

${ }^{3}$ Kwak R, Niizuma H, Ohi T, Suzuki J. Angiographic study of cerebral vasospasm following rupture of 
intracranial aneurysms. Part I. Time of the appearance. Surg Neurol 1979;11:257-62.

${ }^{4}$ Drake CG, in Hunt WE, Hess RM. Surgical risk as related to time of intervention in the repair of intracranial aneurysms. $J$ Neurosurg 1968;28:14-20.

${ }^{5}$ Sano K, Saito I. Timing and indication of surgery for ruptured intracranial aneurysms with regard to cerebral vasospasm. Acta Neurochir (Wien) 1978; $41: 49-60$.

${ }^{6}$ Pakarinen S. Incidence, aetiology and prognosis of primary subarachnoid haemorrhage. Acta Neurol Scand (Suppl) 1967;29.

${ }^{7}$ Mullan S, Dawley J. Antifibrinolytic therapy for intracranial aneurysms. J Neurosurg 1968;28:21-3.

${ }^{8}$ Norlén G, Thulin CA. Antifibrinolytic therapy for bleeding intracranial aneurysms. (Swedish.) Läkartidningen 1968;65:2910-12.

${ }^{9}$ Nibbelink DW. Co-operative aneurysm study: antihypertensive and antifibrinolytic therapy following subarachnoid hemorrhage from ruptured intracranial aneurysm. In: Whisnant JP, Sandok BK, eds. Cerebral vascular disease. New York: Grune and Stratton, 1975:155-73.

${ }^{10}$ Sengupta RP, So SC, Villarejo-Ortega FJ. Use of epsilon-aminocaproic acid (EACA) in the preoperative management of ruptured intracranial aneurysms. $J$ Neurosurg 1976;44:479-84.

11 Chowdhary UM, Carey PC, Hussein MM. Prevention of early recurrence of spontaneous subarachnoid haemorrhage by $\epsilon$-aminocaproic acid. Lancet 1979;1: 741-3.

${ }^{12}$ Norlén G, Thulin CA. The use of antifibrinolytic substances in ruptured intracranial aneurysms. Neurochir 1969;12:100-2.

${ }^{13}$ Gibbs JR, Corkill ALG. Use of an anti-fibrinolytic agent (tranexamic acid) in the management of ruptured intracranial aneurysms. Postgrad Med J $1971 ; 47: 199-200$.

${ }^{14}$ Tovi D. The use of antifibrinolytic drugs to prevent early recurrent aneurysmal subarachnoid haemorrhage. Acta Neurol Scand 1973;49:163-75

15 Fodstad H, Thulin CA. Use of tranexamic acid (AMCA) in the preoperative management of patients with ruptured intracranial aneurysms. In: Carrea R, ed. Sixth International Congress of Neurological Surgery, Sao Paulo, 19-25 June 1977, Abstracts, 244. Amsterdam: Excerpta Medica, 1977.

${ }^{16}$ Fodstad H, Liliequist B, Lindquist M, Schannong M, Thulin CA. The effect of tranexamic acid (AMCA) on radiological cerebral vasospasm following subarachnoid haemorrhage. Acta Neurochir (Wien) 1978;42:247-8.

${ }^{17}$ Chandra B. Treatment of subarachnoid hemorrhage from ruptured intracranial aneurysm with tranexamic acid: a double-blind clinical trial. Ann Neurol 1978;3:502-4.

18 Maurice-Williams RS. Prolonged antifibrinolysis: an effective non-surgical treatment for ruptured intracranial aneurysms? Br Med J 1978;1:945-7.

${ }^{19}$ Schisano G. The use of antifibrinolytic drugs in aneurysmal subarachnoid haemorrhage. Surg Neurol 1978;10:217-22.
${ }^{20}$ Gibbs JR, O'Gorman P. Fibrinolysis in subarachnoid haemorrhage. Postgrad Med J 1967;43:779-84.

${ }^{21}$ Girvin JP. The use of antifibrinolytic agents in the preoperative treatment of ruptured intracranial aneurysms. Trans Am Neurol Assoc 1973;98:150-2.

22 Profeta G, Castellano F, Guarnieri L, Cigliano A, Ambrosio A. Antifibrinolytic therapy in the treatment of subarachnoid haemorrhage caused by arterial aneurysms. J Neurosurg Sci 1975;19:77-8.

${ }^{23}$ van Rossum J, Wintzen AR, Endtz LJ, Schoen JHR, de Jonge $\mathbf{H}$. Effect of tranexamic acid on rebleeding after subarachnoid hemorrhage: a double-blind controlled clinical trial. Ann Neurol 1977;2:238-42.

${ }^{24}$ Kaste M, Ramsay M. Tranexamic acid in subarachnoid haemorrhage: a double-blind study. Stroke 1979;10:519-22.

${ }^{25}$ Botterell EH, Lougheed WM, Scott JW, Vandewater SL. Hypothermia and interruption of carotid, or carotid and vertebral circulation, in the surgical treatment of intracranial aneurysms. $J$ Neurosurg 1956;13:1-42.

${ }^{26}$ Kjellin KG, Söderström CE. Diagnostic significance of CSF spectrophotometry in cerebrovascular diseases. J Neurolog Sci 1974;23:359-69.

${ }^{27}$ Gabrielsen TO, Greitz T. Normal size of the internal carotid, middle cerebral and anterior cerebral arteries. Acta Radiol [Diagn] (Stockh) 1970;10:1-10.

${ }^{28}$ Fodstad H, Liliequist B, Schannong M, Thulin CA. Tranexamic acid in the preoperative management of ruptured intracranial aneurysms. Surg Neurol 1978; 10:9-15.

${ }^{29}$ Vessman J, Strömberg S. Determination of tranexamic acid in biological material by electron capture gas chromatography after direct derivatization in an aqueous medium. Analytical Chemistry 1977;49: 369-73.

${ }^{30}$ Niléhn JE. Split products of fibrinogen after prolonged interaction with plasmin. Thromb Diath Haemorrh 1967;18:89-100.

${ }^{31}$ Tovi D, Nilsson IM, Thulin CA. Fibrinolysis and subarachnoid haemorrhage. Inhibitory effect of tranexamic acid. Acta Neurol Scand 1972;48:393-402.

${ }^{32}$ Fodstad H, Liliequist B. Spontaneous thrombosis of ruptured intracranial aneurysms during treatment with tranexamic acid (AMCA). Acta Neurochir (Wien) 1979;49:129-44.

${ }^{33}$ Fodstad H, Forsell $\AA$, Liliequist B, Schannong M, West KA. Antifibrinolytics and subarachnoid haemorrhage: results from two controlled clinical trials using tranexamic acid (AMCA). 31st Annual Meeting Scandinavian Neurosurgical Society, Oulu, Finland, June 13-16 1979, Abstract 22.

${ }^{34}$ Tsapogas MJ, Cotton LT, Flute PT, Murray JG. The effects of chlorpropamide on intermittent claudication and fibrinolysis. Lancet 1962;1:1213-5.

${ }^{35}$ Tanser AR. Fibrinolytic response to oral glucose. Lancet 1966;2:147-8.

${ }^{36}$ Fearnley GR, Vincent CT, Chakrabarti R. Reduction of blood fibrinolytic activity in diabetes mellitus by insulin. Lancet 1959;2:1067.

${ }^{37}$ Fearnley GR, Chakrabarti R, Vincent CT. Effect of the sulphonylureas on fibrinolysis. Lancet 1960;2:622-5. 
${ }^{38}$ Fearnley GR, Chakrabarti R. Pharmacological enhancement of fibrinolytic activity of blood. $J$ Clin Pathol 1964;17:328-32.

${ }^{39}$ Andersson L, Eriksson O, Hedlund PO, Kjellman H, Lindqvist B. Special considerations with regard to the dosage of tranexamic acid in patients with chronic renal diseases. Urol Res 1978;6:83-8.

${ }^{40}$ Zahavi J, Schwartz G. Chlorpromazine and platelet function. Lancet 1978;2:164.

${ }^{41}$ Carlsson C, Dencker SJ, Grimby G, Häggendal J. Noradrenaline in blood-plasma and urine during chlorpromazine treatment. Lancet 1966;1:1208.

4.2 Genton E, Kern F, Jr, von Kaulla KN. Fibrinolysis induced by pressor amines. Am J Med 1961;31: 564-71.

${ }^{43}$ Holemans R. Enhancement of fibrinolysis in the dog by injection of vasoactive drugs. Am J Physiol 1965;208: 511-20.

${ }^{44}$ Chakrabarti R, Fearnley GR, Hocking ED. Effect of corticosteroid therapy on fibrinolysis in patients with inflammatory and non-inflammatory conditions. Br Med J 1964;1:534-7.

${ }^{45}$ Grishin AI. Dexamethasone and aldosterone action on the blood coagulation system. (Russian.) Farmakol Toksikol 1972;35:90-2.

${ }^{46}$ Simon RA, Schatz M, Stevenson DD, et al. Radiographic contrast media infusions. Measurement of histamine, complement, and fibrin split products and correlation with clinical parameters. J Allergy Clin Immunol 1979;63:281-8.

${ }^{47}$ Lin JP, Kricheff II, Chase NE. Blood pressure changes during retrograde brachial angiography. Radiology 1964;83:640-6.

${ }^{48}$ Kågström E, Palma L. Influence of antifibrinolytic treatment on the morbidity in patients with subarachnoid hemorrhage. Acta Neurol Scand 1972;48:
257-8.

${ }^{49}$ Sonntag VKH, Stein BM. Arteriopathic complications during treatment of subarachnoid hemorrhage with epsilon-aminocaproic acid. J Neurosurg 1974;40: 480-5.

${ }^{50}$ Rydin E, Lundberg PO. Tranexamic acid and intracranial thrombosis. Lancet 1976;2:49.

51 Davies D, Howell DA. Tranexamic acid and arterial thrombosis. Lancet 1977;1:49.

52 Hoffman EP, Koo AH. Cerebral thrombosis associated with Amicar therapy. Radiology 1979;131:687-9.

${ }^{53}$ Norrman SR. The sympathomimetic actions of trans4-amino-methylcyclohexane carboxylic acid (AMCA, Cyklokapron) in anaesthetitized cats. Data on file, AB Kabi, Stockholm.

${ }^{54}$ Ooneda G, Yoshida Y, Takatama M, Sekiguchi M, Kato M. Effect of epsilon-aminocaproic acid as an antifibrinolytic agent on arterial lesions in hypertensive rats with surgically constricted renal arteries. Keio J Med 1962;11:157-64.

${ }^{55} \mathrm{Kwaan}$ HC, Astrup T. Aortic arteriosclerosis in rabbits. Arch Pathol 1964;78:474-82.

${ }^{56}$ Kato N, Morimatsu M, Tanaka K, Horie A. Effects of trans-4-aminomethylcyclohexane carboxylic acid as an antifibrinolytic agent on arterial wall and experimental atherosclerotic lesions in rabbits. Thromb Diath Haemorrh 1970;24:85-99.

57 Knibestöl M, Karadayi A, Tovi D. Echo-encephalographic study of ventricular dilatation after subarachnoid hemorrhage with special reference to the effect of antifibrinolytic treatment. Acta Neurol Scand 1976;54:57-70.

58 Park BE. Spontaneous subarachnoid hemorrhage complicated by communicating hydrocephalus: epsilon-amino caproic acid as a possible predisposing factor. Surg Neurol 1979;11:73-80. 